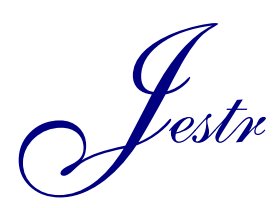

\title{
Fatigue Simulation Analysis of Carriageway Plates of Reinforced Concrete T-Shaped Girders
}

\author{
Chunli Zhang ${ }^{1}$, Wusi Chen ${ }^{1}$, Zhihao Jia ${ }^{2}$, Shuifei Gan ${ }^{3}$, Peng Duan ${ }^{1, *}$ and Binshuang Zheng ${ }^{3}$ \\ ${ }^{1}$ Chongqing Jianzhu College, Chongqing 400072, China \\ ${ }^{2}$ CMCU Engineering Co., Ltd, Chongqing 400039, China \\ ${ }^{3}$ Northeast Forestry University, Haerbin 150040, China
}

Received 22 June 2019; Accepted 1 September 2019

\begin{abstract}
The carriageway plate, which is a bridge structure, directly bears the traffic load and can cause fatigue rupture easily by repeated loading. This study put forward an analysis model of reinforced concrete T-shaped girder carriageway plate girders to reveal the law of the influences of internal factors, such as length-width and thickness-width ratios of two- and one-way slabs, on the fatigue performance of carriageway plates. The physical girder space model was established using the Midas/FEA finite element software. The correlation between the fatigue stress level, length-width ratio, and thickness-width ratio of carriageway plates and the fatigue performance of carriageway plates of ribbed-girder bridges was analyzed using traditional fatigue analysis methods based on the S-N curve and Miner linear cumulative damage theory. The fatigue life and rupture areas were determined. The change rules of fatigue life and damage degrees of structure girders under different influencing factors were determined. Results show that a significant negative correlation exists between the length-width ratio and fatigue life of carriageway plate when the length-width ratio of one-way slabs ranges from 4.0 to 6.0. The fatigue life decreases linearly with the increase in the length-width ratio when the lengthwidth ratio of two-way slabs ranges from 1.0 to 1.9. The anti-fatigue performance of two-way slabs is stronger than that of one-way slabs. In addition, setting the thickness-width ratio of a carriageway plate between 0.07 and 0.08 is economically reasonable. This study provides a certain reference value for the further perfection of the anti-fatigue design of carriageway plates of reinforced concrete ribbed-girder bridges.
\end{abstract}

Keywords: Carriageway plate, Finite element method, Length-width ratio, Fatigue performance

\section{Introduction}

The increases in traffic flow and vehicle tonnage have resulted in fatigue accumulation damage of bridge structures due to cyclic loading, which gradually aggravates bridge fatigue rupture[1]. The carriageway plate, which is an important bridge structure, directly bears the traffic and structurally connects the girder rib and the diaphragm closely to integrate the bridge and transfer live loads to the main girder[2]. Unlike other components, the carriageway plate receives no prestress inside. As a result, fatigue rupture of a carriageway plate can be caused easily, which results in damage to the overall bridge structure. The main form of carriageway plate fatigue rupture is the appearance of cracks and leaks on the plate[3], which can cause unnecessary troubles for the safe and comfortable passage of vehicles. The study on carriageway plate fatigue is important for the research on bridge fatigue. Two safety problems are highly highlighted and mutually contradictory: one is that the bearing capacity of a carriageway plate gradually decreases with the increase in service time of a bridge; and the other is that traffic requires increasing bearing capacity of the carriageway plate, which results in a great imbalance between supply and demand. Leaving these problems

*E-mail address: ii_qino@163.com

ISSN: $1791-2377$ @ 2019 School of Science, HHU. All rights reserved.

doi:10.25103/jestr.125.16 unresolved will cause severe effects on bridge safety[4].

During the design of reinforced concrete bridge structures, designers usually ignore the influences of fatigue performance on the carriageway plate components. However, the fatigue rupture of a reinforced concrete bridge is frequently caused by the fatigue of its carriageway plate[5-8] Therefore, the fatigue damage of the carriageway plate must be evaluated correctly, its damage areas and the degree of accumulated damage must be identified, and the fatigue life of the carriageway plate must be predicted to perform the safety assessment of the entire bridge.

On the basis of the existing research results of reinforced concrete structure fatigue, this study established a physical girder space model with the Midas/FEA finite element software to investigate the carriageway plate fatigue performance by changing the fatigue stress level and lengthwidth and thickness-width ratios of the carriageway plate. Accordingly, a theoretical reference for subsequent experiments and research will be provided.

\section{State of the Art}

Scholars all over the world have conducted numerous researches on the carriageway plate. Batchelor[9] conducted fatigue tests of 37 reinforced concrete carriageway plate models (reduced scale of $1 / 8$ ) at constant frequency and equal amplitude loading and mainly analyzed the law of 
influences of the reinforcement ratio on the carriageway plate fatigue; the maximum fatigue loading that a carriageway plate could bear was obtained at a reinforcement ratio. However, the study did not cover the entire design scope of the reinforcement ratios of carriageway plates. Zhao Shunbo[10] used 22 carriageway plate test pieces for dead load (6 test pieces)and fatigue tests and proposed formulas of normal section fatigue strength and crack width according to the loading features of components. However, the study barely considered the fatigue stress level. On the basis of two types of classical fatigue bike checking model, $\mathrm{Qu} \mathrm{Yu} \mathrm{Y}[11]$ analyzed the change in the principal stress curve of longitudinal and transverse load movements using the finite element method and proposed that the front and rear axle loads and the synergistic effects of vehicle loads on adjacent lanes need not be considered in the fatigue analysis of orthotropic steel bridge plates. However, the proposal was not confirmed by tests. After conducting fatigue tests of concrete cantilever bridge plates under concentrated loads, Natário[12] found that the sensibility of a cantilever bridge plate to shear fatigue rupture was evidently lower than that of a girder without shear reinforcement. However, he did not conduct fatigue analysis under a distributed load. Carvelli[13] conducted studies on reinforcing composite rebar reinforced concrete carriageway plates with glass fiber and found that their anti-fatigue performance was better than that of ordinary concrete slabs. However, the influences of the thickness-width ratio on the fatigue performance were not analyzed intensively. On the basis of a summary of existing structure plate fatigue tests, Pan Yongxiang[14] conducted a theoretical analysis of the normal section fatigue performance of integral bidirectional ribbed hollow slabs and proposed computational and verification formulas of the normal section endurance bending strength of integral bidirectional ribbed hollow slabs. However, the application scope of these formulas is limited. Under the operating conditions of expressway bridges in Brazil, Rodrigues[15] proposed a reinforced concrete bridge fatigue-safety evaluation method and established a traffic load and bridge structure response simulation model considering the important sources of uncertainty. However, the application scope of its load spectrum is limited. Li Xiaojing[16] used the ANSYS finite element software for the numerical analysis of fatigue performance of the steel-concrete composite box girder and discovered the law of influences of parameters, such as thickness of concrete frange plates, concrete strength, girder height, and stud spacing, on the fatigue performance of the steel-concrete composite box girder. However, the fatigue stress level was not discussed in the study. Ma[17] put forward a new crack propagationbased method of reinforced concrete girder aging corrosion fatigue life prediction; the corrosion growth kinetics and fatigue crack growth dynamics were coupled, and the fatigue crack propagation rate curve was accumulated from the equivalent initial defect size to the critical length to predict the fatigue life. However, the discrete development of cracks was not fully discussed. Through the fatigue tests of GFRP reinforced concrete slabs, Zhao Jun[18] put forward that the GFRP reinforcement and compression zone concrete strains and the crack width significantly increased with the fatigue cycles. However, no research on the influences of the length-width ratio on its fatigue mechanism exists. In a clear bending condition, Spathelf[19] studied the fatigue performance of reinforced concrete plates through largescale tests and described the internal force redistribution of sections after the failure of individual reinforcement through the direct measurement of steel strain. However, no evaluation on two- and one-way slabs can be found. Through establishing thermal elastoplastic finite element models and verifying the model test data, Cui Chuang[20] derived the equations of the residual stress distribution of orthotropic steel bridge plate and weld seams on longitudinal rib joints. However, the study did not involve a research on reliability during plate fatigue damage. On the basis of environment temperature, traffic flow, and strain monitoring data, Farreras-AlcoverI[21] set up a fatigue reliability model of an orthotropic bridge deck, derived the $\mathrm{S}-\mathrm{N}$ curves, and applied them to strain monitoring without conducting a detailed diversified assessment of influencing factors. Zhang[22] combined full-scale model tests with finite element analysis, studied the fatigue performance of a new orthotropic steel-concrete (OSCD), and evaluated the influences of concrete and shear stud damage on the OSCD fatigue performance for the first time. However, the difference assessment of fatigue factors is insufficient. Gao $\mathrm{Pu}[23]$ simulated the curvilinear relationship of the local reinforcement stress of carriageway plates with ANSYS, converted on-site traffic volume into reinforcement stress spectrum of carriageway plates using the rain flow counting method, applied Miner's rule to the calculation of the accumulated damage of rebar fatigue, and conducted a comparative analysis of the worst loading position of lanes. However, few studies have been conducted on the influences of the length-width ratio on the carriageway plates.

In summary, scholars have conducted considerable research on the fatigue performance of bridge decks and achieved great results. However, their research on the fatigue performance of reinforced concrete carriageway plates is insufficient and seldom discussed the influence law of internal factors, such as length-width and thicknesswidth ratios of one- and two-way slabs. On the basis of the existing research results on the fatigue of the reinforced concrete structure, this work introduced the design processes of prototype girders and girder models, established a physical model of the girder model space with the Midas/FEA finite element software, and studied the carriageway plate fatigue performance by changing the fatigue stress level and length-width and thickness-width ratios of the carriageway plate. Accordingly, a theoretical reference for subsequent experiments and research will be provided.

The remainder of this study is organized as follows. Section 3 describes the structure of the girder model and presents a finite element analysis model. Section 4 discusses the fatigue analysis of the model by traditional fatigue analysis methods based on the S-N curve and Miner's rule and obtains the change law of fatigue life and damage of carriageway plates under different analysis variables by comparison. The last section summarizes this study and presents the conclusions.

\section{Methodology}

\subsection{Parameters of finite element modeling}

In accordance with the design drawing of the girder model, a finite element space model of two horizontal middle girders was established with one-piece casting applied to the diaphragm. Figure 1 shows the 3D finite element model of an $8 \mathrm{~m}$ T-shaped girder. C40 concrete was made with 3D physical units and ordinary rebar with $1 \mathrm{D}$ girder units. In the 
static analysis, concrete and ordinary rebar were made with isotropous elastic constitutive models [24]. In the fatigue simulation analysis, they were made with anisotropic elastic constitutive models [25].

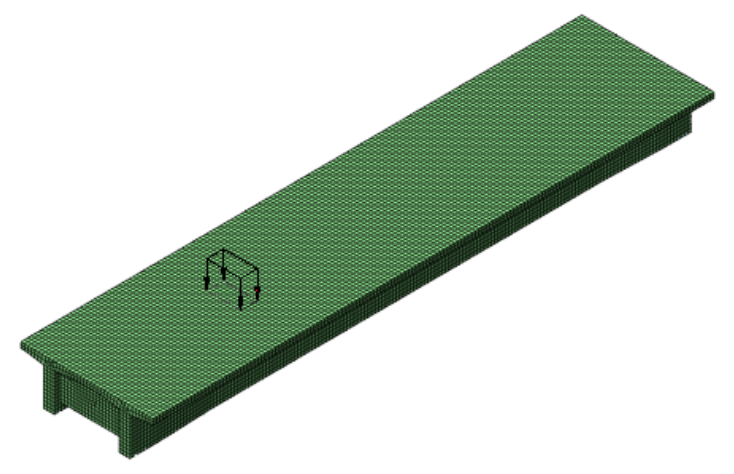

(a) Grid chart of the physical model

$\underbrace{0.000}_{0.683} \frac{1.366}{2.050} 2.733$

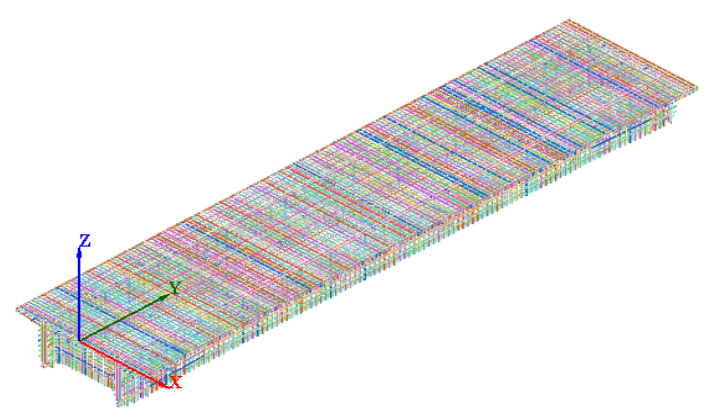

(b) Grid chart of the physical reinforcement cage

Fig. 1. Finite element model

A steel block was placed on the midspan to avoid the excessive concentration of strain. The size of the block was obtained by equivalent calculation in accordance with the action area of the rear wheels and the thickness of the bridge deck pavement in the specifications, that is, $28 \mathrm{~cm} \times 48 \mathrm{~cm}$ $\times 3 \mathrm{~cm}$. The concentrated force was dispersed and transmitted through the steel block to generate an even load on the carriageway plate. Therefore, in the Midas/FEA procedure, the limit load was simulated with an even load of "any quadrilateral load," where the even load was 218.58 $\mathrm{kN} / \mathrm{m} 2$. Figure 2 presents the carriageway plate loading positions of the girder model.

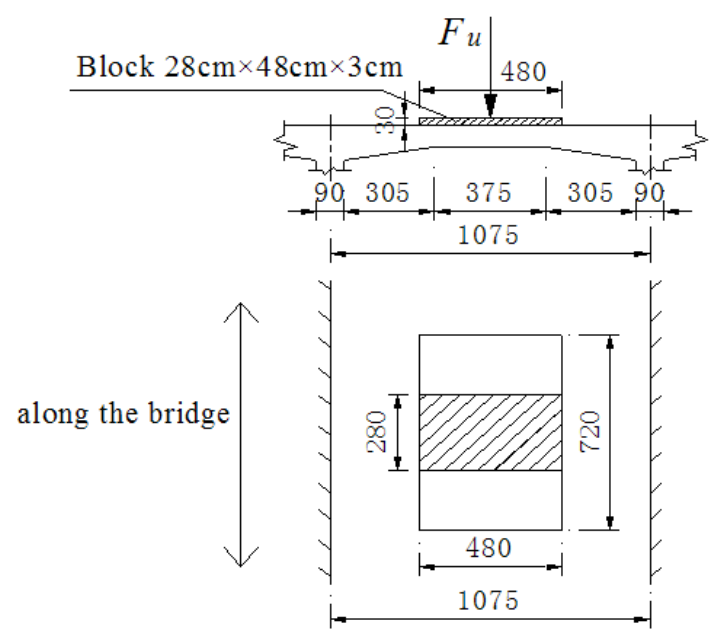

Fig. 2. Carriageway plate loading positions of the girder model (mm)

\subsection{Simulation process of fatigue figures}

The fatigue analysis of the girder model was carried out with fatigue loads of equal stress in consideration of the Von Mises stress and the Goodman and Gerber correction methods in its average stress. The concrete material was simulated with anisotropic elastic constitutive models and the rebar with reinforced double broken line models. The excess width of cracks caused by tension or fatigue cracks caused by reinforcement yielding was used as the standard of component fatigue rupture. Using the finite element model, cloud charts of fatigue life and damage degree of the model girder were obtained (the classical Miner's rule was adopted).

Loading frequency $f$ is empirically set to $5 \mathrm{~Hz}$, and fatigue variation laws are explored without considering the impacts of loading rate. In Midas/FEA, the stress life method based on the $\mathrm{S}-\mathrm{N}$ curves was used to conduct fatigue analysis. Therefore, all strains were supposed to be elastic and the materials were isotropic. On the basis of the loading groups of static analysis, the fatigue functions of dead loads and carriageway plates were created, and the change law of fatigue life and damage degree was analyzed in the worst condition.

The stress amplitudes on structures are the same despite the difference in their mean stresses, and this condition leads to different fatigue lives. Thus, mean stress correction was performed. Goodman and Gerber proposed the following modifier formulas to consider the influences of mean stress on fatigue life. Figure 3 shows the curvilinear relationship between mean stress and stress amplitude.

Goodman correction formula: $\frac{\sigma_{a}}{S_{e}}+\frac{\sigma_{m}}{S_{u}}=1$

Gerber correction formula: $\frac{\sigma_{a}}{S_{e}}+\left(\frac{\sigma_{m}}{S_{u}}\right)^{2}=1$,

Where $\sigma_{a}$ is the stress amplitude, $\sigma_{m}$ is the mean stress $\left(\sigma_{m}=\left(\sigma_{\max }+\sigma_{\min }\right) / 2\right), S_{e}$ is the stress amplitude of fatigue limit, $S_{u}$ is the maximum stress amplitude.

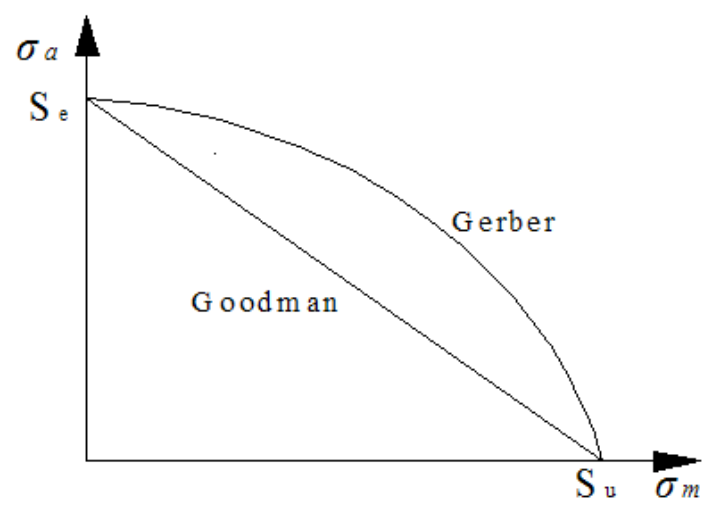

3. Curvilinear relationship between mean stress and stress amplitude

\subsection{Settings of the finite element analysis model}

On the basis of the loading features of carriageway plates, four analysis models were created. Among the four models, the static analysis model was compared with the fatigue analysis model to mainly investigate the influences of the length-width and thickness-width ratios of carriageway plates on the fatigue performance, as shown in Table 1. 
Table 1. Four analysis models

\begin{tabular}{|c|c|c|}
\hline Model & Model variable & Remark \\
\hline 1-static analysis & One-way slab $1_{\mathrm{a}} / 1_{\mathrm{b}}=3.6$, a diaphragm on midspan & Investigate the first principal stress under limit load \\
\hline 2-stress level & $S_{\max }=0.15,0.20, \ldots, 0.75,0.8$ & $\begin{array}{c}\text { Adjust size parameters of carriageway plates under } \\
\text { different stress levels }\end{array}$ \\
\hline $\begin{array}{l}\text { 3-length-width } \\
\text { ratio }\left(1_{a} / l_{b}\right)\end{array}$ & $\begin{array}{l}\text { One-way slab: } 1_{\mathrm{a}} / \mathrm{l}_{\mathrm{b}}=2.0,2.4, \ldots, 6.8,7.2 \\
\text { Two-way slab: } 1_{\mathrm{a}} / \mathrm{l}_{\mathrm{b}}=1.0,1.1, \ldots, 1.8,1.9\end{array}$ & $\begin{array}{c}\text { When } S_{\max }=0.55 \text {, other parameters do not change } \\
\text { investigate damage degree and fatigue life of the } \\
\text { girder model }\end{array}$ \\
\hline $\begin{array}{l}\text { 4-thickness-width } \\
\quad \text { ratio }\left(\mathrm{h} / \mathrm{l}_{\mathrm{b}}\right)\end{array}$ & $\mathrm{h} / \mathrm{l}_{\mathrm{b}}=0.04,0.05, \ldots, 0.10,0.11$ & $\begin{array}{c}\text { When } S_{\max }=0.55 \text {, other parameters do not change; } \\
\text { investigate changes in damage degree and fatigue } \\
\text { life of the girder model }\end{array}$ \\
\hline
\end{tabular}

\section{Result Analysis and Discussion}

\subsection{Result analysis of static simulation}

Specifications of bridge design indicate that an $8 \mathrm{~m} \mathrm{~T}$ shaped girder usually requires three middle diaphragm plates. Thus, the first principal stress of a one-way slab with a

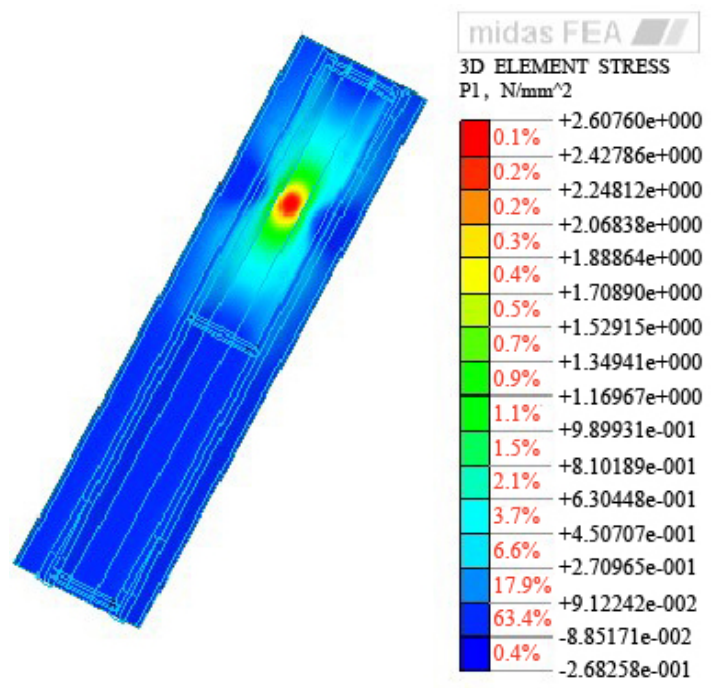

(a) Upward view

Fig. 4. Cloud chart of first principal stress under dead load

Figure 4 shows that the maximal principal stress of the one-way slab was $2.61 \mathrm{MPa}$ under dead load, and the maximal stress value was $2.61 \mathrm{MPa}<f_{c k}=26.8 \mathrm{MPa}$. These values met the design requirements. Figure 4 indicates that the finite element simulation process was reasonable and could provide a basis for further fatigue figure simulation.

\subsection{Influences of the length-width ratio on the fatigue performance of one-way slabs}

Different length-width ratios can lead to different stresses on the upper and lower borders of a one-way slab, which also leads to different fatigue lives according to the preliminary forecast. Therefore, on the basis of the research scheme of the fatigue performance of one-way slabs, fatigue loading simulation was conducted with a length-width ratio ranging from 2.0 to 7.2 (the equal difference was 0.4 ) and $S_{\max }$ ranging from 0.15 to 0.80 . The fatigue lives and rupture areas of one-way slabs of 14 length-width ratios were simulated under 2 million uniform cyclic loads.

\subsubsection{Analysis of fatigue life}

Figure 5 shows the cloud chart of the fatigue life of a oneway slab with $1_{\mathrm{a}} / 1_{\mathrm{b}}=3.6$ when $S_{\max }=0.50$, which indicated that an entire one-way slab generated 16 grades of length-width ratio of 3.6 under the ultimate load was selected to analyze the change law of the stress and deflection of the girder model. When three middle diaphragm plates were set up, the stress cloud chart of the girder model under dead load was obtained, as shown in Figure 4.

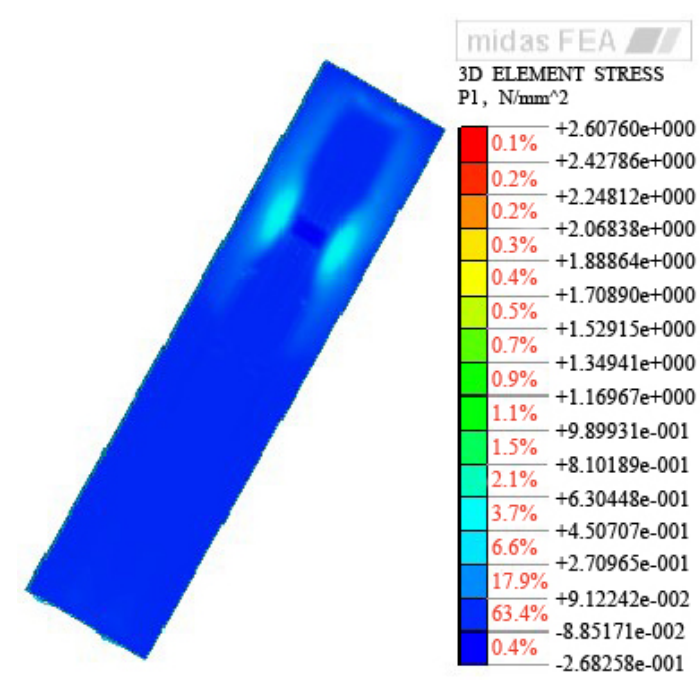

(b) Plan view

fatigue life values. The fatigue rupture first attacked the area formed by the stress concentration position of the lower border of a one-way slab (the junction of the carriageway plate midspan and the haunch end) and the position bearing the cyclic load, which caused the loss of formal function and the decrease in fatigue life. Accordingly, the fatigue life of this area was regarded as that of the one-way slab. The maximal and minimal fatigue lives of a one-way slab with $1_{\mathrm{a}} / 1_{\mathrm{b}}=3.6$ and $S_{\max }=0.50$ were $7.28 \times 10^{7}$ times and 4.55 $\times 10^{6}$ times, respectively. Thus, the fatigue life was 4.55 $\times 10^{6}$ times. The influences of different fatigue stress levels on the fatigue life of one-way slabs were explored. Figure 6 shows the fatigue lives of 14 types of one-way slab.

Figure 6 shows that the fatigue life of one one-way slab decreased with the increase in the fatigue stress level, N. The fatigue life of a one-way slab decreased sharply with the increase in the fatigue stress level when $S_{\max } \leqslant 0.25$, and all fatigue lives were greater than 5 million times. The fatigue life tended toward infinity when the fatigue stress level was near 0 . Therefore, no fatigue appeared on the one-way slabs when $S_{\max } \leqslant 0.25$. In actual bridge engineering, an antifatigue design is unnecessary when the stress generated by vehicle loads on a one-way slab is less than 0.25 . In the 
current study, the fatigue life of a one-way slab decreased evidently with the increase in the fatigue stress level when $0.25<S_{\max } \leqslant 0.55$, but all fatigue lives were greater than 2 million times in accordance with the conventional design requirements. When $S_{\max }>0.55$, the fatigue life decreased evidently. In actual bridge engineering, the fatigue stress level of one-way slabs should not exceed 0.55 to ensure 2 million times of fatigue life and safety.

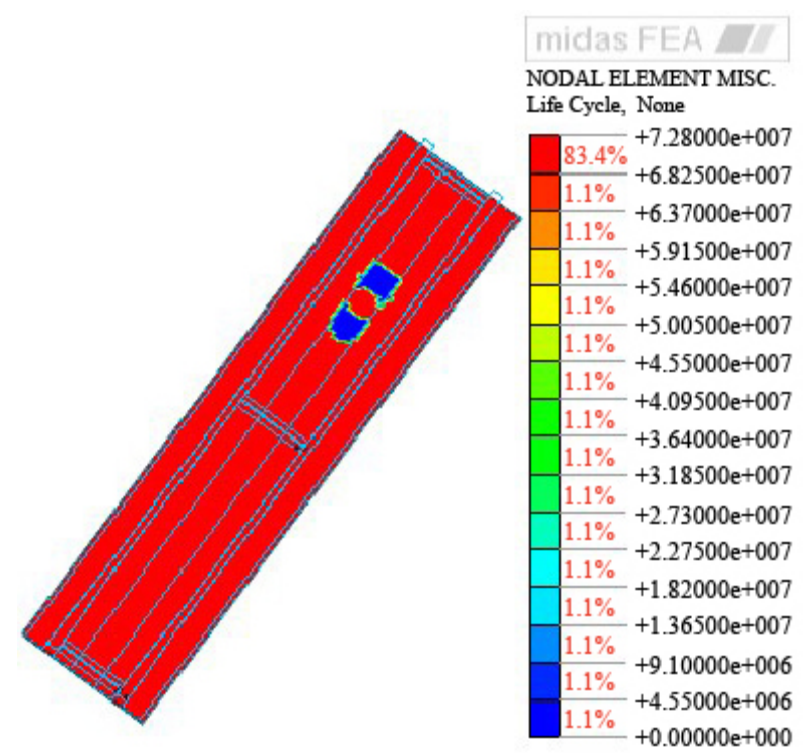

Fig. 5. Cloud chart of fatigue life of a one-way slab with $1_{\mathrm{a}} / \mathrm{l}_{\mathrm{b}}=3.6$ when $S_{\max }=0.50$

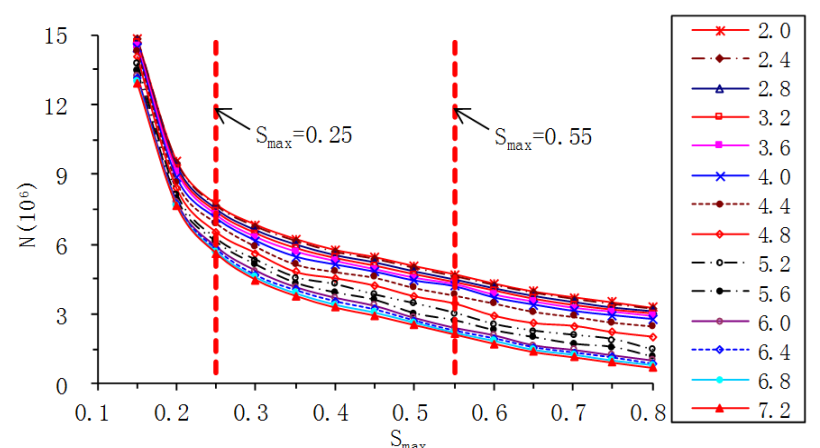

Fig. 6. Curve diagram of fatigue life of one-way slabs on different stress levels

According to conclusions above, the fatigue of one-way slabs was insignificant when $S_{\max } \leqslant 0.25$. Therefore, the fatigue performance of one-way slabs need not be studied when $S_{\max } \leqslant 0.25$. The law of influences of the length width ratios on the fatigue life of one-way slabs was discussed when $0.3 \leqslant S_{\max } \leqslant 0.8$ (Figure 7).

Under the same fatigue stress level, the fatigue life of a one-way slab decreased with the increase in the length width ratio. The increase in the length - width ratio showed low influences on the fatigue life of the one-way slab when $1_{\mathrm{a}} / 1_{\mathrm{b}} \leqslant 4.0$.

Comparing fatigue lives under the same fatigue stress level showed that their difference ratios were no more than $14.06 \%$. When $S_{\max } \leqslant 0.55,1_{\mathrm{a}} / 1_{\mathrm{b}} \leqslant 4.0$ and all fatigue lives of one-way slabs were above 2 million times. Their difference ratios were no more than $12.15 \%$, and the minimum value was $5.12 \times 10^{6}$ times, which was $156 \%$ greater than 2 million times. When $1_{\mathrm{a}} / 1_{\mathrm{b}}$ ranged from 4.0 to 6.0 , the fatigue life of one one-way slab gradually decreased to nearly 2 million times with the increase in the fatigue stress level. When $S_{\max }$ was 0.55 and the length - width ratio was 6.0 , the fatigue life was $2.40 \times 10^{6}$, which was only $20 \%$ greater than 2 million times. When $1_{a} / 1_{b} \geqslant 6.0$, the decrease in fatigue life of a one-way slab gradually became slow with the increase in the length-width ratio and was lower than 2 million times.

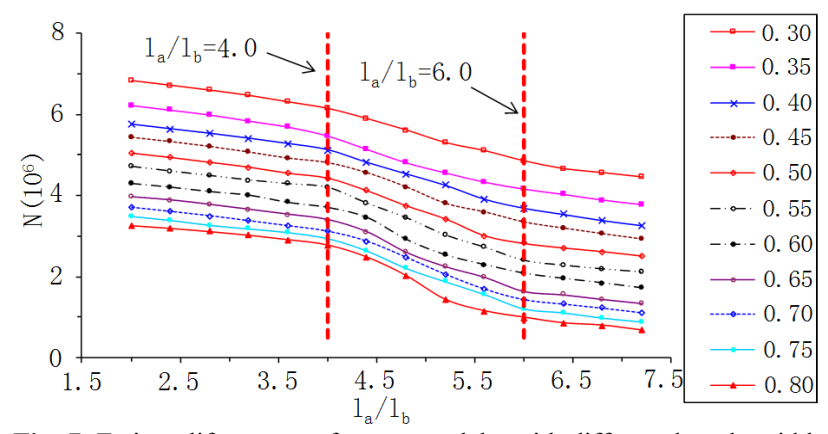

Fig. 7. Fatigue life curves of one-way slabs with different length-width ratios

\subsubsection{Analysis of fatigue rupture areas}

Figure 8 shows the cloud chart of the fatigue damage degree of a one-way slab with $1_{\mathrm{a}} / 1_{\mathrm{b}}=3.6$ when $S_{\max }=0.50$. The first fatigue rupture area of a one-way slab had the highest damage degree. According to Miner's rule, the maximal damage degree was calculated as $\mathrm{D}=1$. $\mathrm{P}$, which is the proportion of the damaged area to the entire carriageway plate of the girder model (\%), changed according to the different fatigue stress levels and length-width ratios. Thus, under a fatigue stress level with significant fatigue (i.e., $S_{\max }$ $\geqslant 0.3$ ), $\mathrm{P}$ was used to indicate the area of fatigue damage (Figure 9). For the same one-way slab, the area of fatigue damage increased with the increase in the fatigue stress level.

Figure 9 indicates that the area of fatigue damage for the same one-way slab increased with the increase in the fatigue stress level. Meanwhile, the area of fatigue damage was related to the increase in the fatigue stress level. Under the same fatigue stress level, the area of fatigue damage increased with the increase in the length-width ratio, as shown in Figure 10.

\subsection{Influences of the length-width ratio on the fatigue performance of two-way slabs}

\subsubsection{Fatigue life analysis}

Fatigue loading of two-way slabs with 10 length-width ratios was carried out when $S_{\max }$ ranged from 0.15 to 0.8 (equal difference $=0.05$ ). Figure 11 shows the fatigue life of a two-way slab with $1_{\mathrm{a}} / 1_{\mathrm{b}}=1.8$ when $S_{\max }=0.50$. Evidently, fatigue rupture started from the lower border of the two-way slab and the damage area focused on the area formed by the stress concentration position (the junction of the carriageway plate midspan and the haunch end) and the position bearing the cyclic load, which was similar to the result for one-way slabs. 


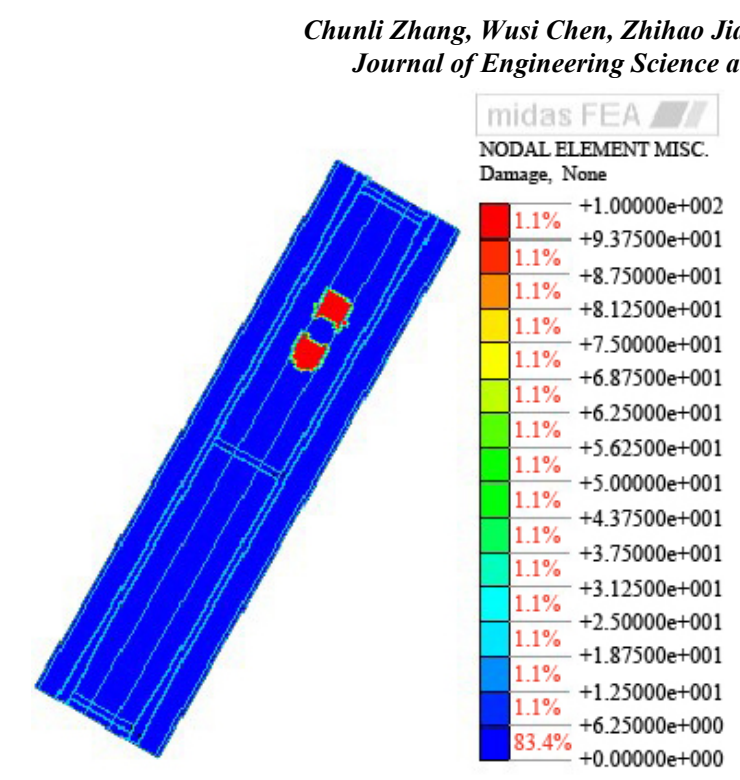

Fig. 8. Cloud chart of the fatigue damage degree of a one-way slab with $\mathrm{l}_{\mathrm{a}} / \mathrm{l}_{\mathrm{b}}=3.6$ when $S_{\max }=0.50$

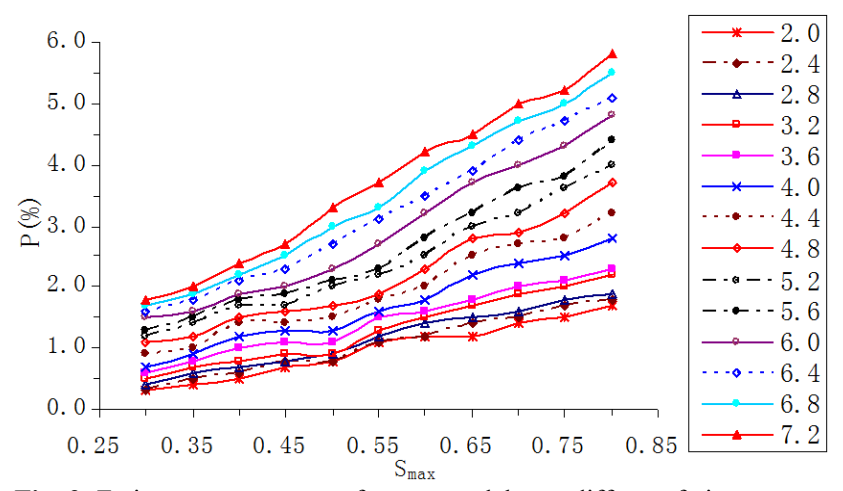

Fig. 9. Fatigue rupture areas of one-way slabs on different fatigue stress levels

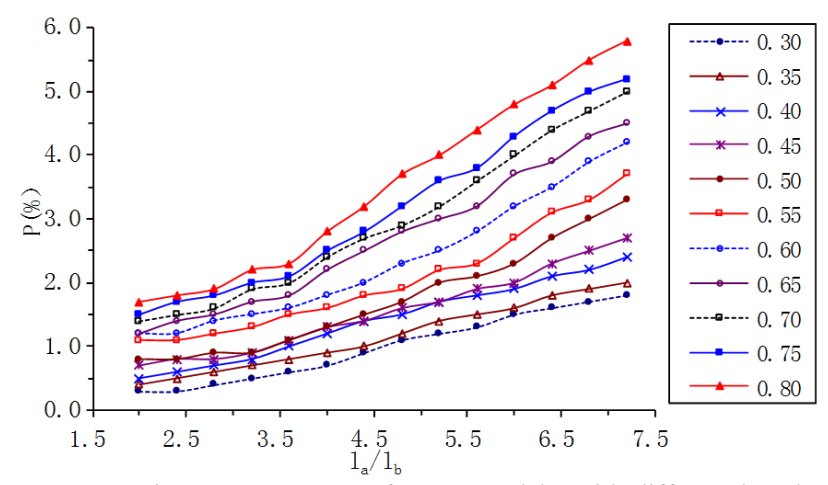

Fig. 10. Fatigue rupture areas of one-way slabs with different lengthwidth ratios

Figure 12 shows the fatigue lives of two-way slabs with 10 length-width ratios. With the increase in the lengthwidth ratio, the change law of the fatigue life of two-way slabs was quite similar to that of one-way slabs. No addition detailed description is presented here due to the limited space of the present study. Similar to the research methods of one-way slabs, the influences of the length - width ratios on the fatigue life of two-way slabs when $0.3 \leqslant S_{\max } \leqslant 0.8$ were determined.

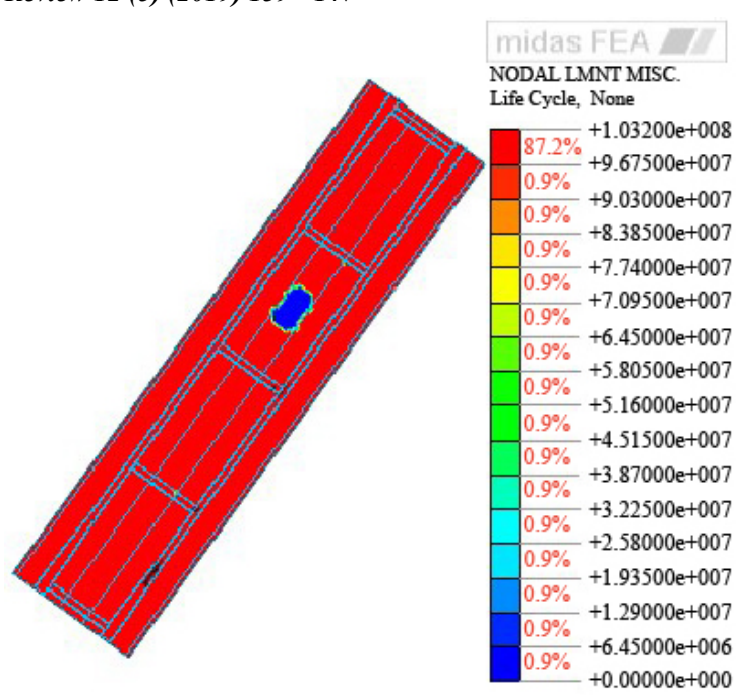

Fig. 11. Fatigue life of a two-way slab with $\mathrm{l}_{\mathrm{a}} / \mathrm{l}_{\mathrm{b}}=1.8$ when $S_{\max }=$ 0.50

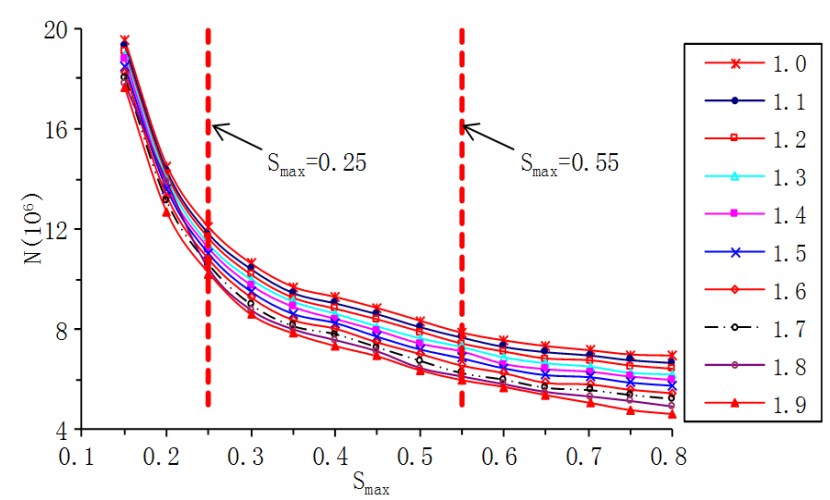

Fig. 12. Fatigue life curve of two-way slabs on different fatigue stress levels

Figure 13 shows that the fatigue life of a two-way slab decreased with the increase in the length-width ratio under the same fatigue stress level. The slope of the curve indicated that the fatigue life tended to linearly change when the length-width ratio was between 1.0 and 1.9.

When $S_{\max }$ was 0.55 , the fatigue life of the two-way slab with $1_{\mathrm{a}} / 1_{\mathrm{b}}=1.9$ was $5.98 \times 10^{6}$; that of the two-way slab with $1_{a} / 1_{b}=1.0$ was $7.86 \times 10^{6}$, which was $23.92 \%$ lower but considerably greater than 2 million times.

From the perspective of structure, small length-width ratio sets correspond to a strong anti-fatigue performance of a two-way slab. However, from the aspect of actual engineering costs and applicability, a small length-width ratio increases the middle diaphragm plates, which increases the cost and the dead load, going against the top and bottom stresses. Therefore, in actual bridge construction, the lengthwidth ratio of two-way slabs should not be too small in view of the principle of safety, economy, and applicability. Comparison between the minimal fatigue life of two-way slabs $\left(1_{a} / 1_{b}=1.9\right)$ and the maximal fatigue life of one-way slabs $\left(1_{\mathrm{a}} / 1_{\mathrm{b}}=2\right)$ under the same fatigue stress level and cyclic load showed that the minimal fatigue life of two-way slabs was $31.43 \%$ higher than that of one-way slabs on average.

In summary, a large length-width ratio of a carriageway plate corresponded to a short fatigue life under the same fatigue stress level. The anti-fatigue performance of two- 
way slabs was stronger than that of one-way slabs under the same fatigue stress level.

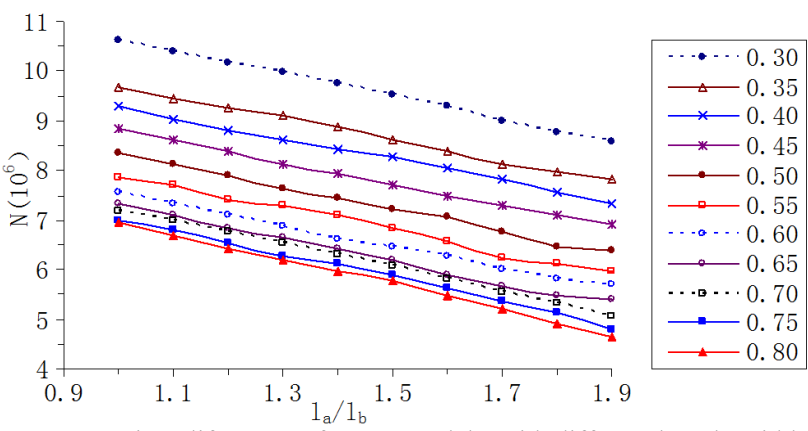

Fig. 13. Fatigue life curve of two-way slabs with different length-width ratios

\subsubsection{Analysis of fatigue rupture areas}

Figure 14 shows the cloud chart of the fatigue rupture area of a two-way slab with $1_{\mathrm{a}} / 1_{\mathrm{b}}=1.8$ when $S_{\max }=0.50$. Figure 14 shows that the fatigue rupture areas of two-way slabs shared similarities to those of one-way slabs. $\mathrm{P}$, which is the proportion of the damaged area to the entire carriageway plate of the girder model (\%), changed according to different fatigue stress levels and length - width ratios. Thus, under a fatigue stress level with significant fatigue (i.e., $S_{\max } \geqslant 0.3$ ), $\mathrm{P}$ was used to indicate the area of fatigue damage. Figures 15 and 16 show the influences of the fatigue stress level and the length-width ratio on the fatigue performance of twoway slabs, respectively. Thus, the area of fatigue damage for the same two-way slabs increased with the increase in the fatigue stress level. In addition, the area of fatigue damage was related to the fatigue stress level. The area of the fatigue damage of two-way slabs increased with the increase in the length-width ratio under the same fatigue stress level. Furthermore, the area of fatigue damage was related to the length-width ratio.

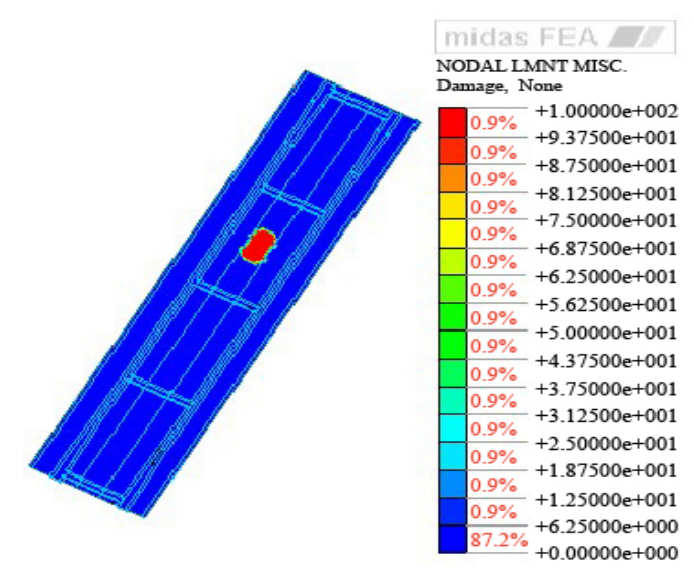

Fig. 14. Cloud chart of the fatigue rupture area of a two-way slab with $1_{\mathrm{a}} / 1_{\mathrm{b}}=1.8$ when $S_{\max }=0.50$

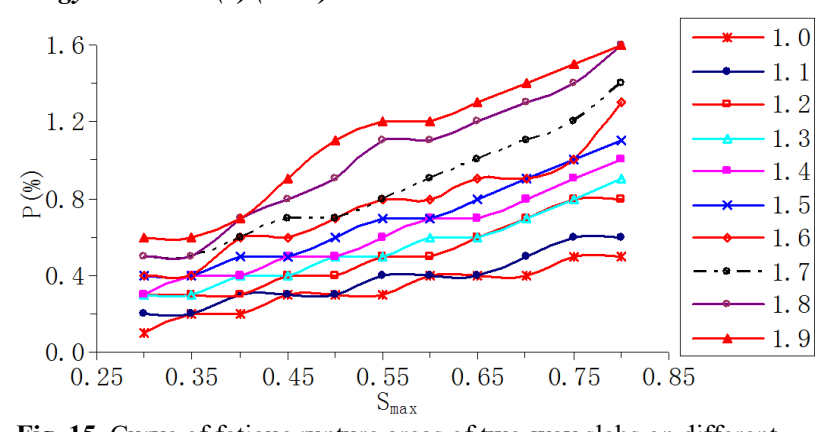

Fig. 15. Curve of fatigue rupture areas of two-way slabs on different fatigue stress levels

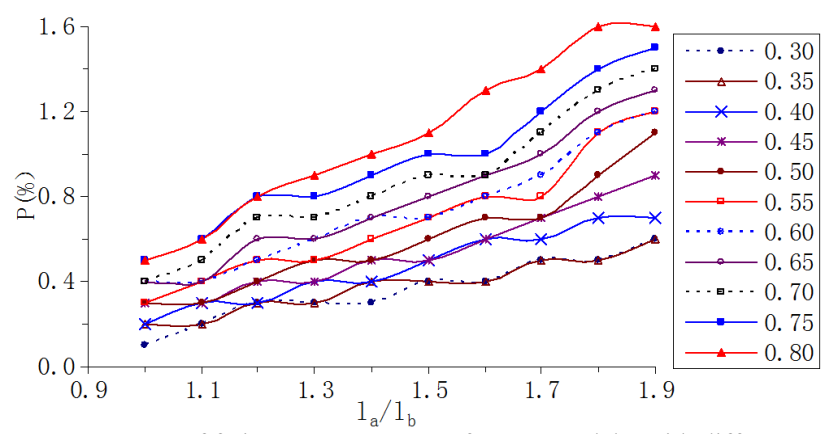

Fig. 16. Curve of fatigue rupture areas of two-way slabs with different length-width ratios

\subsection{Influences of the thickness-width ratio on the fatigue performance of carriageway plates}

\subsubsection{Analysis of fatigue life values}

Fatigue loading of carriageway plates with eight thicknesswidth ratios was carried out when $S_{\max }=0.55$. Table 2 presents the fatigue life values of carriageway plates with eight thickness-width ratios.

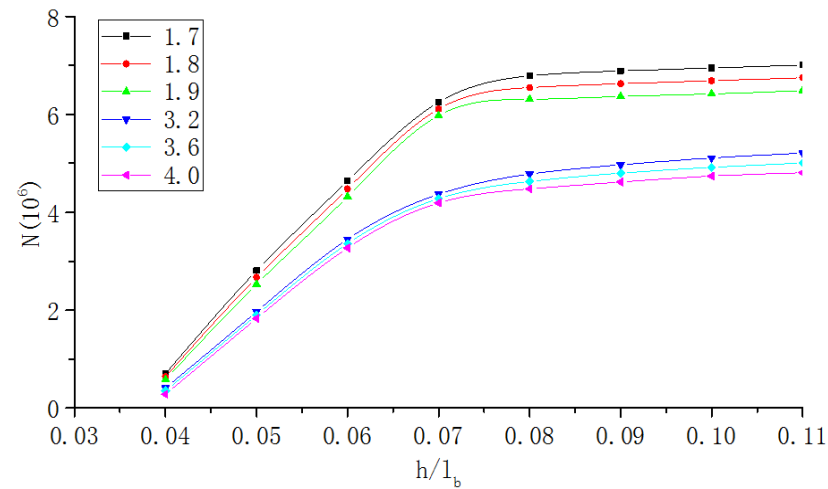

Fig. 17. Fatigue life curve of carriageway plates with different thickness-width ratios when $S_{\max }=0.55$

Table 2. Fatigue life values of carriageway plates with different thickness-width ratios when $S_{\max }=0.55$

\begin{tabular}{|c|c|c|c|c|c|c|c|c|c|}
\hline \multirow{2}{*}{\multicolumn{2}{|c|}{$\begin{array}{l}\text { Length-width ratio } \\
\qquad\left(1_{a} / 1_{b}\right)\end{array}$}} & \multicolumn{8}{|c|}{ Fatigue life $\mathrm{N}\left(10^{6}\right.$ times) with different thickness-width ratios $\mathbf{h} / 1_{\mathrm{b}}$} \\
\hline & & \multirow{2}{*}{$\frac{\mathrm{N}_{0.04}}{0.70}$} & \multirow{2}{*}{$\frac{\mathrm{N}_{0.05}}{2.81}$} & \multirow{2}{*}{$\frac{\mathrm{N}_{0.06}}{4.64}$} & \multirow{2}{*}{$\begin{array}{l}\mathrm{N}_{0.07} \\
6.25\end{array}$} & \multirow{2}{*}{$\frac{\mathrm{N}_{0.08}}{6.79}$} & \multirow{2}{*}{$\frac{\mathrm{N}_{0.09}}{6.89}$} & \multirow{2}{*}{$\frac{\mathrm{N}_{0.10}}{6.95}$} & \multirow{2}{*}{$\frac{\mathrm{N}_{0.11}}{7.01}$} \\
\hline \multirow{3}{*}{ Two-way slab } & 1.7 & & & & & & & & \\
\hline & 1.8 & 0.64 & 2.67 & 4.48 & 6.11 & 6.55 & 6.63 & 6.69 & 6.75 \\
\hline & 1.9 & 0.58 & 2.53 & 4.32 & 5.98 & 6.31 & 6.37 & 6.42 & 6.49 \\
\hline \multirow{3}{*}{ One-way slab } & 3.2 & 0.41 & 1.97 & 3.45 & 4.37 & 4.78 & 4.97 & 5.11 & 5.21 \\
\hline & 3.6 & 0.35 & 1.90 & 3.36 & 4.28 & 4.63 & 4.80 & 4.92 & 5.01 \\
\hline & 4.0 & 0.28 & 1.83 & 3.27 & 4.19 & 4.48 & 4.62 & 4.74 & 4.81 \\
\hline
\end{tabular}

Note: Subscripts of $\mathrm{N}$ in this table refer to the thickness-width ratio of each carriageway plate 
From Figure 17, the following results were observed:

(1) The fatigue lives increased with the same lengthwidth ratio and the increase in the thickness-width ratio of carriageway plates. This result was consistent with the previous conjecture of the present study. With the same length-width ratio, the influences of the thickness-width ratio increase of carriageway plates on the fatigue life increase were significant when $\mathrm{h} / \mathrm{l}_{\mathrm{b}}<0.07$; the increase rate of the fatigue life slowed down gradually when $0.07 \leqslant \mathrm{~h} / 1_{\mathrm{b}}$ $\leqslant 0.08$; the fatigue life tended to level change when $\mathrm{h} / \mathrm{l}_{\mathrm{b}}>$ 0.08 .

(2) Comparison between carriageway plates with $\mathrm{h} / \mathrm{l}_{\mathrm{b}}$ $\geqslant 0.08$ (Table 3) showed that the maximal fatigue life difference was only $8.29 \%$, and the minimal fatigue life was considerably greater than the 2 million times required in actual engineering. Thus, the thickness-width ratio of carriageway plates should be increased. Further increase in the thickness-width ratio would increase the overall dead load of the bridge structure, going against the overall stress of the girder structure. Therefore, $\mathrm{h} / \mathrm{l}_{\mathrm{b}}$ of carriageway plates should be no more than 0.08 in view of safety, economy, and applicability.

(3) Comparison of fatigue lives of $\mathrm{h} / \mathrm{l}_{\mathrm{b}}=0.07$ and $\mathrm{h} / \mathrm{l}_{\mathrm{b}}$ $=0.08$ (Table 3 ) for the same carriageway plate showed that the maximal difference was only $8.54 \%$, and the minimal fatigue life was $109.5 \%$ greater than the 2 million times required in actual engineering when the thickness-width ratio was 0.07 . In actual engineering, setting the thicknesswidth ratio between 0.07 and 0.08 is economically reasonable, which indicates the correctness of the common thickness-width ratios applied to standard drawing.

Table 3. Fatigue life data of carriageway plates when $\mathrm{h} / \mathrm{l}_{\mathrm{b}} \geqslant 0.07$

\begin{tabular}{|c|c|c|c|c|c|c|c|c|c|}
\hline \multirow{2}{*}{\multicolumn{2}{|c|}{$\begin{array}{l}\text { Length-width ratio } \\
\qquad\left(\mathrm{l}_{\mathrm{a}} / 1_{\mathrm{b}}\right)\end{array}$}} & \multicolumn{6}{|c|}{ Fatigue life $\mathrm{N}$ ( $10^{6}$ times) with different thickness-width ratios $\mathrm{h} / \mathrm{l}_{\mathrm{b}}$} & \multirow{2}{*}{$\left(\mathrm{N}_{\max }-\mathrm{N}_{0.08}\right) / \mathrm{N}_{\max }$} & \multirow{2}{*}{$\left(\mathrm{N}_{0.08}-\mathrm{N}_{0.07}\right) / \mathrm{N}_{0.08}$} \\
\hline & & $\mathrm{N}_{0.07}$ & $\mathrm{~N}_{0.08}$ & $\mathrm{~N}_{0.09}$ & $\mathrm{~N}_{0.10}$ & $\mathrm{~N}_{0.11}$ & $\mathrm{~N}_{\max }$ & & \\
\hline \multirow{3}{*}{ Two-way slab } & 1.7 & 6.25 & 6.79 & 6.89 & 6.95 & 7.01 & 7.01 & $3.14 \%$ & $7.95 \%$ \\
\hline & 1.8 & 6.11 & 6.55 & 6.63 & 6.69 & 6.75 & 6.75 & $2.97 \%$ & $6.64 \%$ \\
\hline & 1.9 & 5.98 & 6.31 & 6.37 & 6.42 & 6.49 & 6.49 & $2.79 \%$ & $5.23 \%$ \\
\hline \multirow{3}{*}{ One-way slab } & 3.2 & 4.37 & 4.78 & 4.97 & 5.11 & 5.21 & 5.21 & $8.29 \%$ & $8.54 \%$ \\
\hline & 3.6 & 4.28 & 4.63 & 4.80 & 4.92 & 5.01 & 5.01 & $7.60 \%$ & $7.54 \%$ \\
\hline & 4.0 & 4.19 & 4.48 & 4.62 & 4.74 & 4.81 & 4.81 & $6.86 \%$ & $6.47 \%$ \\
\hline
\end{tabular}

Note: Subscripts of $\mathrm{N}$ in this table refer to the thickness-width ratio of each carriageway plate

\subsubsection{Analysis of fatigue rupture areas}

Fatigue loading of carriageway plates with eight thicknesswidth ratios was carried out when $S_{\max }=0.55$ to study the law of influences of the thickness-width ratio of carriageway plates on their fatigue rupture areas. Table 4 shows the fatigue rupture areas of carriageway plates with eight thickness-width ratios. For carriageway plates with the same length-width ratio, the fatigue rupture area decreased with the increase in the thickness-width ratio.

Table 4. Fatigue rupture areas of carriageway plates with different thickness-width ratios when $S_{\max }=0.55$

\begin{tabular}{|c|c|c|c|c|c|c|c|c|c|}
\hline \multirow{2}{*}{\multicolumn{2}{|c|}{$\begin{array}{l}\text { Length-width ratio } \\
\qquad\left(\mathrm{l}_{\mathrm{a}} / \mathrm{l}_{\mathrm{b}}\right)\end{array}$}} & \multicolumn{8}{|c|}{ Fatigue rupture area $\mathrm{P}(\%)$ with different thickness-width ratios $\mathrm{h} / \mathrm{l}_{\mathrm{b}}$} \\
\hline & & \multirow{2}{*}{$\frac{\mathrm{N}_{0.04}}{1.2}$} & \multirow{2}{*}{$\frac{\mathrm{N}_{0.05}}{1.0}$} & \multirow{2}{*}{$\frac{\mathrm{N}_{0.06}}{0.9}$} & \multirow{2}{*}{$\frac{\mathrm{N}_{0.07}}{0.8}$} & \multirow{2}{*}{$\frac{\mathrm{N}_{0.08}}{0.6}$} & \multirow{2}{*}{$\frac{\mathrm{N}_{0.09}}{0.4}$} & \multirow{2}{*}{$\frac{\mathrm{N}_{0.10}}{0.3}$} & \multirow{2}{*}{$\frac{\mathrm{N}_{0.11}}{0.2}$} \\
\hline \multirow{3}{*}{ Two-way slab } & 1.7 & & & & & & & & \\
\hline & 1.8 & 1.4 & 1.2 & 1.1 & 1.1 & 0.7 & 0.6 & 0.4 & 0.3 \\
\hline & 1.9 & 1.5 & 1.4 & 1.2 & 1.2 & 0.9 & 0.8 & 0.6 & 0.4 \\
\hline \multirow{3}{*}{ One-way slab } & 3.2 & 1.7 & 1.5 & 1.4 & 1.3 & 1 & 0.9 & 0.6 & 0.4 \\
\hline & 3.6 & 1.8 & 1.7 & 1.6 & 1.5 & 1.2 & 0.9 & 0.7 & 0.5 \\
\hline & 4.0 & 1.9 & 1.8 & 1.7 & 1.6 & 1.3 & 1.0 & 0.8 & 0.6 \\
\hline
\end{tabular}

Note: Subscripts of $\mathrm{N}$ in this table refer to the thickness-width ratio of each carriageway plate

\section{Conclusions}

This study established a 3D space model of reinforced concrete T-shaped girder bridges with the Midas/FEA finite element software to reveal the fatigue performance of carriageway plates of this type of bridge. The change rules of fatigue life and damage degree of carriageway plates were discussed with analysis variables, such as fatigue stress levels, length-width ratios, and thickness-width ratios of carriageway plates. The following conclusions were drawn:

(1) A significant negative correlation exists between the length-width ratio and fatigue life of carriageway plate when the length-width ratio of one-way slabs ranges from 4.0 to 6.0 ; the negative correlation weakens when the length-width ratio of one-way slabs is less than 4.0 or greater than 6.0.

(2) The fatigue life decreases linearly with the increase in the length-width ratio when the length-width ratio of two-way slabs ranges from 1.0 to 1.9.

(3) The minimal fatigue life of two-way slabs is $31.43 \%$ higher than that of one-way slabs on the average. The maximum growth rate of fatigue rupture areas of two-way slabs is $25.16 \%$ lower than that of one-way slabs with the increase in the length-width ratio. The anti-fatigue performance of two-way slabs is stronger than that of oneway slabs.

(4) Setting the thickness-width ratio of a carriageway plate between 0.07 and 0.08 is economically reasonable.

This study regarded the influence of carriageway plates on the fatigue performance of medium-and-small-span 
reinforced concrete ribbed-girder bridges as its main objective, discussed the rules of influences of carriageway plates on the overall bridge fatigue in different structure forms and stress level conditions, and proposed economically reasonable fatigue stress levels, length-width ratios of two- and one-way slabs, and thickness-width ratios of carriageway plates. However, the lack of measuring data of girder fatigue loading tests of indoor scale models suggests that the future study should consider the revised data of girder fatigue loading tests of indoor scale models to carry out in-depth research on the change rules of fatigue life and damage degrees of carriageway plates.

\section{Acknowledgements}

This work was supported by the Construction Science and Technology Plan Project of Chongqing (Construction and Scientific 2018 Project No. 1-5-3)

This is an Open Access article distributed under the terms of the Creative Commons Attribution License

\section{References}

1. Park J Y, Kim H K, "Fatigue life assessment for a composite box girder bridge". International Journal of Steel Structures, 14(4), 2014, pp. 843-853.

2. Zheng D W, Zhang Y H, Li G H, et al, "Numerical Analysis of Reinforced Concrete Bridge Panel Fatigue Based on Midas". Advanced Materials Research, 838-841, 2014, pp. 1048-1053.

3. Mondoro A, Soliman M, Frangopol D M, "Prediction of structural response of naval vessels based on available structural health monitoring data". Ocean Engineering, 125, 2016, pp. 295-307.

4. Chen Y, Zhou J T and Zhang $\mathrm{H}$ et al, "Real-time fatigue state evaluation of concrete bridges in service". Journal of Wuhan University of Technology, 36(1), 2014, pp. 108-111.

5. Tong L, Liu B, Xian Q, et al, "Experimental study on fatigue behavior of Steel Reinforced Concrete (SRC) beams". Engineering Structures, 123, 2016, pp. 247-262.

6. Yan G., "Study on fatigue numerical analysis method of reinforced concrete bridge slab". Master thesis of Tianjin University, China, 2010, pp.34-40.

7. Liang J, Nie X, Masud M, et al, "A study on the simulation method for fatigue damage behavior of reinforced concrete structures". Engineering Structures, 150, 2017, pp. 25-38.

8. Cheng R, "Study on the fatigue life of reinforced concrete platform for load - bearing machine". Master thesis of Inner Mongolia University of Science and Technology, China, 2015, pp. 8-10.

9. Batchelor B. Dev, and Hewitt B. E., "Are Composite Bridge Slabs Too Conservatively Designed? - Fatigue Studies". ACI Special Publication, (41), 1974, pp. 331-346.

10. Zhao S B, "Experimental study on fatigue behavior of reinforced concrete slabs with normal section". Journal of Applied Fundamentals and Engineering Science, 7(3), 1999, pp. 289-297.

11. Qu Y, "Study on fatigue Mechanism of orthotropic Bridge Deck of Steel Box girder". Doctoral Dissertation of Chongqing Jiaotong University, China, 2018, pp. 16-17.

12. Natário F, Ruiz M F, Muttoni A, "Experimental investigation on fatigue of concrete cantilever bridge deck slabs subjected to concentrated loads". Engineering Structures, 89, 2015, pp. 191203.

13. Carvelli V, Pisani M A, Poggi C, "Fatigue behaviour of concrete bridge deck slabs reinforced with GFRP bars". Composites Part B Engineering, 41(7), 2010, pp. 560-567.
14. Pan Y X, Wu F B, Jiang Wen and Li Jun, "Fatigue behavior analysis of assembly integral bi-directional multi-ribbed hollow plate". Journal of Architectural Science and Engineering, 35(05), 2018, pp. 109-117.

15. Rodrigues J F S, Casas J R, Almeida P A O, "Fatigue-safety assessment of reinforced concrete (RC) bridges: application to the Brazilian highway network". Structure \& Infrastructure Engineering, 9(6), 2013, pp. 601-616.

$16 \mathrm{Li} \mathrm{X} \mathrm{J,} \mathrm{"Study} \mathrm{on} \mathrm{fatigue} \mathrm{behavior} \mathrm{of} \mathrm{steel-concrete} \mathrm{composite} \mathrm{box}$ girder". Master thesis of Central South University, China, 2014, pp. 25-27.

17. Ma Y, Xiang Y, Wang L, et al, "Fatigue life prediction for aging RC beams considering corrosive environments". Engineering Structures, 79, 2014, pp. 211-221.

18. Zhao J, Wu H, Sun H X and Zhang F, "Experimental study on fatigue behavior of normal section of GFRP reinforced concrete slab". Journal of Hebei University of Technology, 44(05), 2015, pp. 115-118.

19. Spathelf C A, Vogel T, "Fatigue performance of orthogonally reinforced concrete slabs: Experimental investigation". Engineering Structures, 168, 2018, pp. 69-81.

20. Cui C, "Study on fatigue life evaluation method and reliability of steel bridge deck and longitudinal rib connection details based on strain energy". Doctoral Dissertation of Southwest Jiaotong University, China, 2018, pp. 35-38.

21. Farreras-Alcover I, Chryssanthopoulos M K, Andersen J E, "Databased models for fatigue reliability of orthotropic steel bridge decks based on temperature,traffic and strain monitoring". International Journal of Fatigue, 95, 2017, pp. 104-119.

22. Zhang Q, Liu Y, Bao Y, et al, "Fatigue performance of orthotropic steel-concrete composite deck with large-size longitudinal Ushaped ribs". Engineering Structures, 150, 2017, pp. 864-874.

23. Gao $\mathrm{P}, \mathrm{Wu} \mathrm{C}$ and $\mathrm{Su} \mathrm{Q} \mathrm{T}$ et al, "Fatigue damage degree of concrete deck of continuous wide box composite girder bridge". Journal of Jiangsu University, 34(1), 2013, pp. 91-95.

24. Lin H W and Zhao Y X, "Research on the bonding behavior between deformed reinforcement and concrete". Journal of Architectural Structure, 40(01), 2019, pp. 11-27.

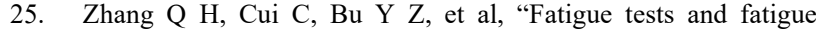
assessment approaches for rib-to-diaphragm in steel orthotropic decks". Journal of Constructional Steel Research, 114, 2015, pp. 110-118 